\title{
HOST CONTROLLED VARIATION IN BACTERIAL VIRUSES ${ }^{1}$
}

\author{
G. BERTANI AND J. J. WEIGLE
}

Department of Bacteriology, University of Illinois, Urbana, Illinois and Kerckhoff Laboratories of Biology, California Institute of Technology, Pasadena, California

Received for publication June 17, 1952

Passage through new hosts or new tissues is a widely used method for altering the properties of viruses. In some instances selection of spontaneous mutants has been demonstrated to be the mechanism causing the variation (Luria, 1945). Nonhereditary mechanisms sometimes have been postulated, but since no such case has been analyzed sufficiently, it is often assumed that selection of mutants is the only possible mechanism. A detailed analysis of two cases of variation in two different bacterial viruses is reported in this paper. In both these cases we are dealing with nonheritable alterations stemming directly from passage through a new host and not with mutations. A somewhat similar case of host controlled variation involving other bacterial viruses has been reported recently by Luria and Human (1952).

\section{MATERIAL AND METHODS}

Bacteria. The following bacterial strains were used: (a) Escherichia coli, strain S, a nonlysogenic derivative of strain K-12 (Weigle and Delbrück, 1951); (b) $E$. coli, strain C (no. 122 of the National Collection of Type Cultures, London); (c) Shigella dysenteriae, strain Sh (Bertani, 1951); (d) $E$. coli, strain B. A derivative of C, strain $\mathrm{C} / 1,5$, resistant to phages $\mathrm{T} 1$ and $\mathrm{T} 5$, and a streptomycin resistant derivative of $\mathrm{Sh}$, strain $\mathrm{Sh} / \mathrm{s}$, were also used.

Phages. The following bacteriophages were

1 This work was supported by grants from the American Cancer Society, as recommended by the Committee on Growth of the National Research Council, and from The National Foundation for Infantile Paralysis. The authors are greatly indebted to Miss Shirley J. Nice for assistance; to Dr. Margaret Lieb for contributing information on phage desorption; to Dr. R. K. Appleyard for contributing data on the distribution of the "exceptional" plaques formed by $\lambda C$ on $S$; and finally to Drs. Max Delbrück and S. E. Luria for discussing the manuscript. used: (a) phage P2, isolated from a lysogenic strain of $E$. coli (Bertani, 1951); (b) phage $\lambda$, isolated from the lysogenic strain K-12 of $E$. coli; (c) phages of the well known T1-T7 series.

Both P2 and $\lambda$ are temperate phages, that is, upon infection of sensitive bacteria, they may form stable lysogenic complexes.

Phage P2 grows normally on strains Sh, Sh/s, and $\mathrm{C}$. It requires $\mathrm{Ca}^{++}$for adsorption. Its sensitivity to ultraviolet radiation is intermediate between that of phage T1 and that of T4. A number of mutants of P2 have also been used. One of them, a virulent mutant (vir), does not form lysogenic complexes. Whereas the plaques of the parental form are turbid, owing to overgrowth of lysogenic bacteria formed in the course of the development of the plaque, the plaques of P2 vir are perfectly clear.

Phage $\lambda$ forms plaques with equal efficiency on strains $\mathrm{S}$ and $\mathrm{C}$. Better plaques are obtained on C than on S. It is very resistant to ultraviolet radiation (Weigle and Delbrück, 1951).

Lysogenic bacteria. Lysogenic strains can be isolated from the bacterial growth visible in the centers of plaques formed by temperate phages. Derivatives of $\mathrm{C}$ and Sh, lysogenic for phage P2, are designated $\mathrm{C}(\mathrm{P} 2)$ and $\mathrm{Sh}(\mathrm{P} 2)$. The isolation of $C(\lambda)$ strains will be described later. During growth, all these strains liberate phage in amounts roughly proportional to the number of bacteria. In $C(\lambda)$, but not in $C(P 2)$ or in $\mathrm{Sh}(\mathrm{P} 2)$, a mass production of phage can be obtained by ultraviolet irradiation ("induction"; Lwoff, Siminovitch, and Kjeldgaard, 1950).

Media and techniques. The experimental techniques were those commonly used in phage work (Adams, 1950). Strains S and C and their derivatives were grown in tryptone broth; aerated cultures, near to their maximum titers, were used for phage platings. For solid media, agar was added to tryptone broth (Difco). A very thick layer of bottom agar is required in plating phage $\lambda$ on strain $\mathrm{S}$. The composition of these media and 
of the phosphate buffer used is given by Weigle and Delbrück (1951). Strain Sh and its derivatives were grown in tryptone broth enriched with yeast extract (LB), and strain $B$, unless otherwise noted, was grown in nutrient broth (Difco). The composition of these media is given by Bertani (1951). All P2 phage platings were done on LB agar, using overnight aerated cultures as plating bacteria. All preparations of P2, unless otherwise noted, were either lysates made on Sh or $\mathrm{Sh} / \mathrm{s}$ or filtered supernatants from cultures of $\mathrm{Sh}(\mathrm{P} 2)$. All preparations of $\lambda$ were ultraviolet induced lysates from K-12 cultures, purified by differential centrifugation, and resuspended in phosphate buffer with added $\mathbf{M g}^{++}$. derivatives. This modified form of phage $\lambda$ will be called $\lambda C$. The high efficiency of the transformation excludes the possibility of interpreting $\lambda C$ as a mutant of $\lambda$.

Comparison of the properties of $\lambda$ and $\lambda C$. Using a lysate of phage $\lambda C$ obtained as described in table 1 , a lysogenic strain $\mathrm{C}(\lambda \mathrm{C})$ was isolated. Preparations of $\lambda \mathrm{C}$ were made by inducing cultures of $\mathrm{C}(\lambda \mathrm{C})$ with ultraviolet and purifying the lysates.

A comparison of the properties of $\lambda$ and of $\lambda C$ gave the following results: (a) Ultraviolet irradiation inactivates $\lambda$ and $\lambda C$ at the same rate, at least down to a survival of $10^{-3}$. (b) Rabbit antiserum against $\lambda$ inactivates both $\lambda$ and $\lambda C$ at the

\section{TABLE 1}

\section{Transformation of phage $\lambda$ into phage $\lambda C$ : one cycle growth experiment}

Bacteria from overnight cultures of Escherichia coli, strains $\mathbf{S}$ and $\mathbf{C}$, were infected with phage $\lambda$ at $37 \mathrm{C}$. Twenty minutes were allowed for adsorption. Phage assays were made before and after lysis, by plating on strain $S$ and on strain C. A sample from the adsorption mixture was diluted before lysis and centrifuged. The supernatant was assayed on both indicators for unadsorbed phage.

\begin{tabular}{|c|c|c|c|c|}
\hline 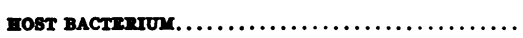 & \multicolumn{2}{|c|}{$\mathbf{s}$} & \multicolumn{2}{|c|}{ C } \\
\hline Input bacteria. & \multicolumn{2}{|c|}{$2 \times 10^{0}$} & \multicolumn{2}{|c|}{$2 \times 10^{0}$} \\
\hline & Plaque counts on $S$ & Plaque counts on $C$ & Plaque counts on $S$ & Plaque counts on $C$ \\
\hline Input phage $\ldots \ldots \ldots \ldots \ldots$ & $3.4 \times 10^{8}$ & $3.5 \times 10^{8}$ & $2.3 \times 10^{8}$ & $2.2 \times 10^{8}$ \\
\hline Infective centers before lysis. & $3.5 \times 10^{8}$ & $3.7 \times 10^{8}$ & $3.1 \times 10^{7}$ & $2.0 \times 10^{8}$ \\
\hline Unadsorbed phage $\ldots \ldots \ldots \ldots \ldots$ & $3.6 \times 10^{6}$ & $3.4 \times 10^{6}$ & $1.1 \times 10^{7}$ & $1.0 \times 10^{7}$ \\
\hline Infective centers after lysis..... & $2.3 \times 10^{10}$ & $2.5 \times 10^{10}$ & $3.2 \times 10^{7}$ & $1.6 \times 10^{10}$ \\
\hline
\end{tabular}

The ultraviolet lamp and the technique used for induction of lysogenic strains have been described by Weigle and Delbrück (1951).

\section{VARIATION IN PHAGE $\lambda$}

Growth of phage $\lambda$ in strains $S$ and $C$ and its transformation into $\lambda C$. Plating equal amounts of phage $\lambda$ on strains $S$ and $C$ gives equal plaque counts. The phage produced in $\mathbf{C}$ cells infected with $\lambda$, however, is different from that produced in $S$ cells: it has lost its ability to grow in $S$ cells while retaining the ability to grow in $\mathrm{C}$ cells. One growth cycle in $\mathrm{C}$ is sufficient to produce this change (table 1). The change, as observed, is incomplete since a very small number of plaques are still produced on $\mathbf{S}$ by the phage liberated by $\mathbf{C}$ cells. This point will be discussed below.

Similar results are obtained if strain $C / 1,5$ or strain $\mathrm{C}(\mathrm{P} 2)$ is used instead of C. The ability to propagate phage $\lambda$ in a form unable to grow in $\mathrm{S}$ is thus a general property of strain $\mathrm{C}$ and of its same rate. (c) Temperature inactivation in phosphate buffer already is measurable at room temperature and proceeds at the same rate for both phages. Both are protected by $\mathrm{Mg}^{++}$. (d) Latent period (ca $50 \mathrm{~min}$ ) and burst size (ca 100) on strain $\mathrm{C}$ are identical for the two phages. (e) No morphological differences between $\lambda$ and $\lambda C$ have been noticed with the electron microscope.

Centrifugation experiments showed that $\lambda$ and $\lambda C$ adsorb equally well on strain $S$ (table 2 ). The incomplete inactivation of the adsorbed $\lambda C$, however, suggested that $\lambda C$, once adsorbed onto $S$ cells, may slowly desorb and later be able to form plaques when put in contact with $\mathrm{C}$ cells on the plate. This is not peculiar to $\lambda C$ on $S$ since repeated centrifugations of $\mathrm{C}$ cells with adsorbed $\lambda$ or $\lambda C$ also indicate desorption. The conditions affecting desorption were not investigated.

Since $\lambda C$ adsorbs well on $S$ without multiplying, other effects of $\lambda \mathrm{C}$ on $\mathrm{S}$ were looked for. The killing ability was tested by exposing a sample 
from an $\mathrm{S}$ culture $\left(10^{9}\right.$ cells per $\left.\mathrm{ml}\right)$ to a tenfold excess of $\lambda \mathrm{C}$ at $37 \mathrm{C}$ in broth and allowing 20 min for adsorption. Bacterial assays after adsorption did not differ from assays of a noninfected control sample kept at $37 \mathrm{C}$ for the same length of time: that is, neither bacterial killing nor any delay in bacterial growth was observed.

-The $\mathrm{S}$ cells which adsorb $\lambda \mathrm{C}$ phages, without being killed, do not become lysogenic, or, if they do so at all, the proportion of lysogenic cells is lower than that obtained with $\lambda$. Two samples of a culture of $S$ were infected with $\lambda$ and $\lambda C$, respectively. After serum inactivation of the un-

\section{TABLE 2}

Adsorption and inactivation of phage $\lambda C$ by Escherichia coli, strain S

Two samples of a fully grown culture of strain $S$ were infected with phages $\lambda$ and $\lambda C$, respectively. After allowing $20 \mathrm{~min}$ for adsorption at $37 \mathrm{C}$, platings were made immediately for total infective centers. Two hours later a dilution of the adsorption mixture was plated for assay of progeny phage. Aliquots of the adsorption mixtures were centrifuged and the supernatants were assayed for unadsorbed phage. All platings were made on $\mathrm{C}$.

\begin{tabular}{|c|c|c|}
\hline & \multicolumn{2}{|c|}{ INFECTING PHAGE } \\
\hline & $\lambda \mathbf{C}$ & $\boldsymbol{\lambda}$ \\
\hline Input phage. & $9.2 \times 10^{7}$ & $3.5 \times 10^{8}$ \\
\hline Total infective centers. & $1.3 \times 10^{7}$ & $3.7 \times 10^{8}$ \\
\hline Unadsorbed phage..... & $1.3 \times 10^{8}$ & $3.4 \times 10^{6}$ \\
\hline $\begin{array}{c}\text { Plaque counts after } 2 \\
\text { hours } \ldots \ldots \ldots \ldots \ldots\end{array}$ & $1.5 \times 10^{7}$ & $2.5 \times 10^{10}$ \\
\hline Burst size $\ldots \ldots \ldots \ldots \ldots \ldots$ & - & 68 \\
\hline
\end{tabular}

adsorbed phage, they were plated for surviving, colony forming bacteria. These colonies were tested for lysogenesis. Among $132 \lambda$ surviving colonies 10 were found to be lysogenic $S(\lambda)$, while no lysogenic colonies were found among 124 $\lambda \mathrm{C}$ surviving colonies tested.

Thus, except for the inability of $\lambda \mathrm{C}$ to grow on $S$, no difference was noticed between $\lambda$ and $\lambda C$ in all these tests. The fate of $\lambda \mathrm{C}$ after adsorption onto $S$ remains unknown.

Transformation of $\lambda C$ into $\lambda$. Preparations of $\lambda \mathrm{C}$ obtained from induced $\mathrm{C}(\lambda \mathrm{C})$ or from a single growth cycle of $\lambda \mathrm{C}$ on $\mathrm{C}$ have not lost completely the ability to plate on $\mathrm{S}$. They usually give about one plaque on $\mathrm{S}$ for $5 \times 10^{3}$ plaques on $\mathrm{C}$. The phage present in the few plaques produced on $S$ behaves like typical $\lambda$ : it plates with equal efficiency on $S$ and $C$ and when used to infect $C$ it again gives origin to $\lambda \mathrm{C}$ progeny.

The few plaques on $S$ may represent (1) mutant phage particles, (2) physiological phage variants, or (3) standard $\lambda \mathrm{C}$ particles which infect exceptional cells of strain S. In the second and third case, one should assume further that passage through $\mathrm{S}$ causes a reverse transformation of $\lambda \mathrm{C}$ into $\lambda$.

The third view is supported by the fact that the proportion of plaques formed on $\mathrm{S}$ by $\lambda \mathrm{C}$ is in-

TABLE 3

Transformation of phage $\lambda C$ into phage $\lambda$ in ultraviolet irradiated cells of Escherichia coli, strain $S$

A fully grown culture of strain $\mathbf{S}$ was centrifuged and resuspended in buffer. Samples were irradiated with ultraviolet for different lengths of time, assayed by colony counts for surviving bacteria, and used as plating bacteria $(0.5 \mathrm{ml}$ per plate) to assay a preparation of phage $\lambda C$ having a titer of $2.6 \times 10^{7}$ per $\mathrm{ml}$ on $\mathrm{C}$. Ten plaques from the 300 sec point were sampled and when replated gave equal plaque counts on $S$ and on $C$, thus behaving like typical phage $\lambda$.

\begin{tabular}{c|c|c|c}
\hline $\begin{array}{c}\text { ULTRAVIOLET } \\
\text { DOSE }\end{array}$ & $\begin{array}{c}\text { SURVIVING } \\
\text { BACTERIA }\end{array}$ & $\begin{array}{c}\text { SURVIVING } \\
\text { BACTERIA }\end{array}$ & $\begin{array}{c}\text { PHAGE TITER } \\
\text { MEASURE ON } \\
\text { IRRADIATED S }\end{array}$ \\
\cline { 2 - 3 } 0 & $2.7 \times 10^{9}$ & 100 & $6.6 \times 10^{8}$ \\
$75 \mathrm{sec}$ & $2.2 \times 10^{9}$ & 81 & $7.0 \times 10^{4}$ \\
$150 \mathrm{sec}$ & $1.3 \times 10^{9}$ & 50 & $1.6 \times 10^{5}$ \\
$300 \mathrm{sec}$ & $4.8 \times 10^{8}$ & 18 & $2.1 \times 10^{5}$ \\
$450 \mathrm{sec}$ & $4.4 \times 10^{8}$ & 1.7 & $9.1 \times 10^{4}$ \\
\hline
\end{tabular}

creased by ultraviolet pretreatment ${ }^{2}$ of the $\mathrm{S}$ cells used for plating (table 3). Presumably the ultraviolet treatment changes the physiological conditions of the cells, allowing a larger number of them to accept $\lambda \mathrm{C}$ and transform it into $\lambda$.

Transformation of $\lambda$ into $\lambda C$ in lysogenic bacteria. A lysogenic bacterium carries as prophage the genetic material of the phage employed in making it lysogenic. Hence, by comparing the composi-

2 This experiment was tried after it was discovered that both phages $\lambda$ and $\lambda C$, inactivated by ultraviolet, give a larger plaque count on ultraviolet irradiated bacteria ( $\mathrm{S}$ or $\mathrm{C}$ ) than on nonirradiated bacteria. This does not happen for the phages of the $T$ series. 
tion of the phage yield of a $C(\lambda)$ strain (C made lysogenic with $\lambda)$ with that of a $C(\lambda C)$ strain (C made lysogenic with $\lambda C$ ) one might be able to test for participation of the genetic material of the phage in determining the type of phage liberated. Comparing the lysogenic strains rather than the sensitive $C$ cells infected with $\lambda$ and $\lambda C$, respectively, has the advantage of avoiding contamination of the progeny phage with infecting phage released by desorption, which would

\section{TABLE 4}

Comparison of the phage produced by lysogenic strains $C(\lambda)$ and $C(\lambda C)$

The strain $C(\lambda)$ was prepared by infecting $C$ with $\lambda$ (multiple infection), plating for surviving bacteria before lysis, and picking lysogenic colonies. The strain $\mathrm{C}(\lambda \mathrm{C})$ has been described in the text. Lysates from ultraviolet induced $C(\lambda)$ and $\mathbf{C}(\lambda \mathrm{C})$ cultures were plated on $\mathrm{C}$ and $\mathrm{S}$. The ratios (number of plaques on $\mathrm{S}$ )/(number of plaques on C) are listed for three different experiments. For comparison, the same ratio is given for the phage yield of $\mathbf{C}$ cells infected with $\lambda C$ (one growth cycle).

\begin{tabular}{|c|c|c|}
\hline & \multicolumn{2}{|c|}{ INDUCED BACTERTA } \\
\hline & $C(\lambda C)$ & $C(\lambda)$ \\
\hline Experiment 1 & $2.3 \times 10^{-4}$ & $5.9 \times 10^{-1}$ \\
\hline 2 & $2.0 \times 10^{-4}$ & $3.3 \times 10^{-4}$ \\
\hline 3 & $1.0 \times 10^{-4}$ & $1.0 \times 10^{-4}$ \\
\hline $3^{*}$ & $4.1 \times 10^{-4}$ & $1.1 \times 10^{-}$ \\
\hline $\mathbf{C}$ infected with $\lambda \mathbf{C}$ & \multicolumn{2}{|c|}{$2.5 \times 10^{-4}$} \\
\hline
\end{tabular}

* The lysates of experiment 3 were replated after being kept in refrigerator for 24 hours. This duplication gives an idea of the fluctuation of these measurements from day to day.

make the data unreliable in the case of infection with $\lambda$.

Within the range of the experimental errors the composition of the phage yield of the lysogenic strains tested is independent of the type of phage used to make them lysogenic (table 4), that is, no transfer of the $\lambda$ property through the prophage condition was detected. These experiments make the hypothesis of a genetic difference between $\lambda$ and $\lambda C$ phages very unlikely.

\section{VARIATION IN PHAGE P2}

Origin of PQB. Plating phage P2 on $E$. coli, strain $B$, yields only one plaque for about $10^{5}$ that the same amount of P2 would form on $S$. dysenteriae, strains $\mathrm{Sh}$ or $\mathrm{Sh} / \mathrm{s}$. Under constant plating conditions the proportion of P2 plaques on B is fairly constant with all preparations of P2 and of its mutants; for example, seven preparations of $P 2$, made independently, when plated on $B$, gave ratios (number of plaques on $B$ ) /(number of plaques on $\mathrm{Sh} / \mathrm{s})$ between $3.3 \times 10^{-6}$ and $2.5 \times 10^{-5}$. In another experiment a lysate of P2 and a lysate of the P2 vir mutant gave ratios $7.1 \times 10^{-5}$ and $7.4 \times 10^{-5}$.

The plaques formed by $\mathrm{P} 2$ on $\mathrm{B}$, resuspended in broth and assayed for phage, give approximately equal plaque counts on either strain,

\section{TABLE 5}

Adsorption of phage $P Q$ and phage $P \& B$ on Shigella dysenteriae, strain Sh, and Escherichia coli, strain $B$

Log phase bacteria were resuspended in LB medium with added $0.008 \mathrm{M} \mathrm{CaCl}_{2}$ and mixed with phage. Adsorption was stopped at $10 \mathrm{~min}$ by diluting in cold medium. After centrifugation the supernatant was assayed for unadsorbed phage.

\begin{tabular}{|c|c|c|}
\hline PEAGE & BACTRRTA & $\begin{array}{c}\text { PROPOXTION } \\
\text { OF INPUT } \\
\text { PHAGE } \\
\text { ONADSORBED } \\
\text { ATTER } 10 \text { MTI } \\
\text { AT } 37 \text { C }\end{array}$ \\
\hline P2 & Sh $24 \times 10^{3}$ cells per $\mathrm{ml}$ & $\%$ \\
\hline P2B & Sh, $2.4 \times 10^{8}$ cells per $\mathrm{ml}$ & 2.4 \\
\hline P2 & $\mathrm{B}, 2.8 \times 10^{8}$ cells per $\mathrm{ml}$ & 5.4 \\
\hline P2B & B, $2.8 \times 10^{8}$ cells per $\mathrm{ml}$ & 4.5 \\
\hline
\end{tabular}

$\mathrm{Sh} / \mathrm{s}$ or $\mathrm{B}$. That is, the phage produced in B cells infected with P2 differs from the original P2 by its ability to form plaques on B. This property is transmitted indefinitely as long as phage transfers are made on $B$. This modified phage is designated as P2B. We shall see presently that P2B is not a host range mutant for $\mathrm{P} 2$; rather, the change P2 to P2B is analogous to the change $\lambda C$ to $\lambda$.

Comparison of the properties of $P \&$ and $P \& B$. Lysates of P2B grown on B were compared with lysates of P2 grown on Sh/s. A rabbit antiserum against P2 inactivated $\mathrm{P2}$ and $\mathrm{P} 2 \mathrm{~B}$ at the same rate. Heat resistance (proportion of survivors after exposure to $58 \mathrm{C}$ in LB broth) and ultraviolet resistance (proportion of survivors after exposure of phage diluted in saline to a germicidal lamp) are similar for P2 and P2B. The only 
established difference between P2 and P2B is that the latter multiplies normally in B, while $\mathrm{P} 2$ does not. P2 and P2B adsorb equally well on $B$ and on Sh (table 5), but only very few, if any, of the B cells infected with $\mathrm{P} 2$ are killed by it (table 6).

One step growth experiments with P2B were done by infecting log phase cells of Sh and of $B$ whereas the phage liberated by $B$ infected with P2B, being typical P2B, gives approximately equal counts on B and on Sh. Thus, growth on Sh causes a reverse transformation of $\mathrm{P} 2 \mathrm{~B}$ to the P2 form. The fact that phage produced by Sh infected with P2B gives more plaques on B than other P2 lysates does not mean necessarily that

\section{TABLE 6}

\section{Killing ability of phage $P Z$ on Escherichia coli, strain $B$}

Strain B cells from a nutrient broth culture in exponential phase were added to various concentrations of P2 at $37 \mathrm{C}$. After 5 min allowed for adsorption the mixtures were plated for colony count of surviving bacteria. Samples were also diluted in cold broth and centrifuged: the supernatants were assayed to determine the amount of unadsorbed phage. From these data, the expected survival was calculated on the assumption that each P2 particle kills the B cell on which it is adsorbed.

\begin{tabular}{|c|c|c|c|c|}
\hline Input bacteria $\ldots \ldots \ldots \ldots \ldots \ldots \ldots \ldots \ldots \ldots \ldots \ldots$ & $1.9 \times 10^{8}$ & $1.9 \times 10^{8}$ & $1.9 \times 10^{8}$ & $1.9 \times 10^{8}$ \\
\hline $\begin{array}{c}\text { Average number of phage particles adsorbed per } \\
\text { bacterium } \ldots \ldots \ldots \ldots \ldots \ldots \ldots \ldots \ldots\end{array}$ & & 355 & 0 71 & 0.355 \\
\hline 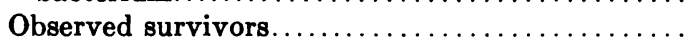 & $1.8 \times 10^{8}$ & $2.0 \times 10^{8}$ & $1.9 \times 10^{8}$ & $1.8 \times 10^{8}$ \\
\hline Expected surviving bacteria.. & $1.6 \times 10^{5}$ & $5.5 \times 10^{6}$ & $9.3 \times 10^{7}$ & $1.3 \times 10^{8}$ \\
\hline
\end{tabular}

\section{TABLE 7}

\section{Transformation of phage $P 2 B$ into phage $P 2$}

The host cells were grown in LB broth and then infected with either one of two preparations of P2B, in presence of $\mathrm{CaCl}_{2}$. The adsorption mixture was diluted then in $\mathrm{LB}$ medium containing antiphage serum to inactivate the unadsorbed phage. A new dilution was made before lysis, from which phage assays were made after lysis, by plating on streptomycin resistant Shigella dysenteriae, strain $\mathrm{Sh} / \mathrm{s}$, and on Escherichia coli, strain B.

\begin{tabular}{|c|c|c|c|c|}
\hline \multirow{2}{*}{$\begin{array}{c}\text { INFICTING } \\
\text { PHAGI }\end{array}$} & & \multicolumn{3}{|c|}{ HOST CELL STRATN } \\
\hline & & Sh & $\mathrm{Sh} / \mathrm{s}$ & $\mathbf{B}$ \\
\hline $\mathbf{P} 2 \mathrm{~B}\left({ }^{\prime}\right)$ & $\begin{array}{l}\text { Approximate number of cells lysed } \\
\text { Plaque count after lysis, on } \mathrm{Sh} / \mathrm{s} \\
\text { Plaque count after lysis, on } \mathrm{B}\end{array}$ & $\begin{array}{l}2.2 \times 10^{8} \\
2.3 \times 10^{10} \\
7.5 \times 10^{7}\end{array}$ & $\begin{array}{l}1.2 \times 10^{8} \\
9.0 \times 10^{9} \\
2.5 \times 10^{7}\end{array}$ & $\begin{array}{l}1.5 \times 10^{8} \\
7.6 \times 10^{9} \\
9.8 \times 10^{9}\end{array}$ \\
\hline $\mathrm{P} 2 \mathrm{~B}\left({ }^{\prime \prime}\right)$ & $\begin{array}{l}\text { Approximate number of cells lysed } \\
\text { Plaque count after lysis, on } \mathrm{Sh} / \mathrm{s} \\
\text { Plaque count after lysis, on } \mathrm{B}\end{array}$ & $\begin{array}{l}1.6 \times 10^{7} \\
4.4 \times 10^{9} \\
4.0 \times 10^{6}\end{array}$ & & $\begin{array}{l}1.3 \times 10^{7} \\
2.0 \times 10^{9} \\
1.4 \times 10^{9}\end{array}$ \\
\hline
\end{tabular}

P2B (') is an isolate of P2, differing from it by four mutational steps (to be described in a future publication) and propagated on $B$.

$\mathrm{P} 2 \mathrm{~B}\left({ }^{\prime \prime}\right)$ is a virulent mutant of $\mathrm{P} 2$, propagated on $\mathrm{B}$.

in LB medium at $37 \mathrm{C}$. The latent period in both cases was approximately 32 minutes, the same as for P2 on Sh. The burst size for P2B on Sh was similar to that of P2 on Sh (70 to 300 ); the burst size of $\mathrm{P} 2 \mathrm{~B}$ on $\mathrm{B}$ grown in LB was somewhat smaller (40 to 150 ).

Transformation of $P Q B$ into $P \mathscr{T}$. The phage liberated by Sh infected with $P 2 B$ gives five hundred times fewer plaques on B than on Sh, the transformation from P2B into P2 effected in one growth cycle by $\mathrm{Sh}$ cells is incomplete since plaques on $B$ may be due to a delayed desorption of a proportion of the input $\mathrm{P} 2 \mathrm{~B}$ phage reversibly adsorbed onto the Sh cells.

Two different mutants of P2B growing on Sh and $\mathrm{Sh} / \mathrm{s}$ were used in these experiments (table 7). Both phage mutants were transformed from the P2B into the P2 form by a single cycle of growth 
in either bacterial strain. The transforming ability is therefore a general property of Sh cells and is independent of the mutant of P2 used. transformation of P2 into P2B are not spontaneous mutants of P2. This was confirmed by the following experiment.

\section{TABLE 8}

\section{a. Distribution of phage P2B plaques formed by a series of cultures of phage P2 propagated} on Shigella dysenteriae, strain Sh

Log phase Sh cells were infected with P2 (multiplicity of infection ca 5), then diluted into LB broth containing antiphage serum to inactivate the unadsorbed phage. Before lysis, the suspension was diluted further and distributed in 66 tubes in $0.5 \mathrm{ml}$ volumes. These samples were incubated at $37 \mathrm{C}$ and plated on strain $B$ after lysis (the whole content of a tube on a plate). Another dilution from the serum tube was used to measure the total number of bacteria lysed and the total amount of phage liberated.

\begin{tabular}{|c|c|c|c|}
\hline \multirow{2}{*}{$\begin{array}{l}\text { NOMGER } \\
\text { OF P2B } \\
\text { PLAQUES } \\
\text { PER TUBE }\end{array}$} & \multicolumn{2}{|c|}{ NOMBER OF TUBES } & \\
\hline & $\begin{array}{c}\text { Ob- } \\
\text { served }\end{array}$ & $\begin{array}{l}\text { Expected } \\
\text { (Poisson) }\end{array}$ & \\
\hline 0 & 14 & 15.5 & \multirow{7}{*}{ 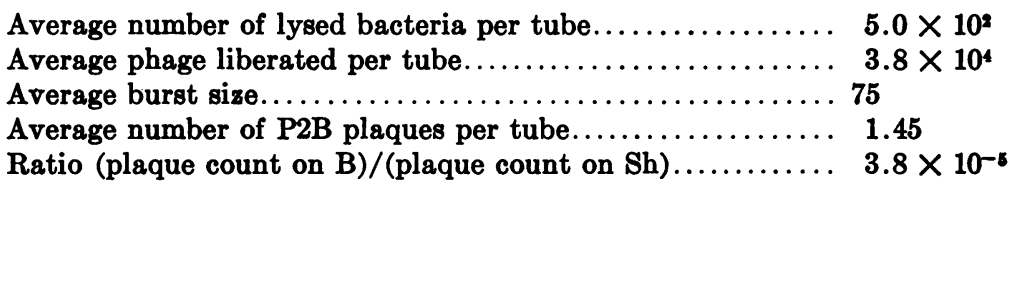 } \\
\hline 1 & 25 & 22.5 & \\
\hline 2 & 16 & 16.3 & \\
\hline 3 & 5 & 7.9 & \\
\hline 4 & 6 & & \\
\hline$>4$ & 0 & 0.8 & \\
\hline Total. & 66 & 66.0 & \\
\hline
\end{tabular}

\section{b. Distribution of phage P2B plaques formed by phage produced in a series of cultures of Shigella dysenteriae, strain Sh(P2)}

Log phase $\mathrm{Sh}(\mathrm{P} 2)$ cells were washed by centrifugation (to eliminate most of the free P2 present in the culture), diluted and distributed in 60 tubes in $0.5 \mathrm{ml}$ volumes. These samples were incubated at $37 \mathrm{C}$ for $6: 30$ hours, during which time the cells grew and liberated some phage. The tubes were heated then at $50 \mathrm{C}$ for 1 hour to kill the bacteria; this treatment, which would not inactivate phage alone, caused also loss of about one-half the phage present, presumably due to readsorption onto the bacteria. Finally, the content of each tube was plated on strain B. Separate dilutions from the washed suspensions of Sh(P2) cells were used to measure the number of cells and the total amount of phage before and after incubation.

\begin{tabular}{|c|c|c|c|c|}
\hline \multirow{2}{*}{$\begin{array}{l}\text { NUTBER } \\
\text { OF P2B } \\
\text { PIAQUES } \\
\text { PER TUBE }\end{array}$} & \multicolumn{2}{|c|}{ NOMBER OF TUBES } & & \\
\hline & $\underset{\text { served }}{\text { Ob- }}$ & $\begin{array}{c}\text { Expected } \\
\text { (Poisson) }\end{array}$ & & \\
\hline $\mathbf{0}$ & 32 & 32.9 & \multirow{6}{*}{ 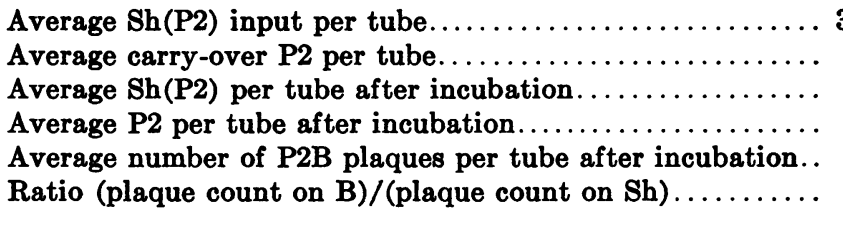 } & 366 \\
\hline 1 & 21 & 19.7 & & 0.75 \\
\hline 2 & 6 & 5.9 & & $1.1 \times 10^{7}$ \\
\hline 3 & 1 & & & $2.9 \times 10^{4}$ \\
\hline$>3$ & 0 & 1.4 & & \\
\hline Total. & 60 & 59.9 & & \\
\hline
\end{tabular}

Nonmutational origin of $P \mathscr{B}$. The fact that P2B does not reproduce as such in Sh, but is always transformed into P2 within one growth cycle, suggests that the few particles in P2 lysates which propagate on $B$ and give rise to the reverse
Variants arising by mutation show a characteristic frequency distribution in series of clones of the parent organism (Luria and Delbrück, 1943; Lea and Coulson, 1949). An analysis of the frequency distribution of the $r$ mutants of 
phage T2 by Luria (1951) showed that they are distributed as expected from the spontaneous mutation hypothesis. With a similar technique we have studied the frequency distribution of P2B plaques produced by plating individual clones of P2, derived either by infection of Sh with $\mathrm{P} 2$ or by liberation from the lysogenic strain $\mathrm{Sh}(\mathrm{P} 2)$. The results, reported in table 8, show that the distribution of the P2B plaques closely approaches a Poisson rather than a clonal distribution. If the few plaques formed on $B$ were due to

\section{TABLE 9}

Mixed infection of Escherichia coli, strain B, with vhage $P 2$ mutants

About $2 \times 10^{8} \mathrm{~B}$ cells in the exponential phase of growth were mixedly infected with $\mathrm{P} 2$ and a plaque type mutant of $\mathrm{P} 2$ in such amounts that the large majority of cells were infected with at least one particle of each kind. The infected cells were plated on $B$, and a random sample of the plaques formed was picked and tested for phage type by replating on $\mathrm{Sh} / \mathrm{s}$.

\begin{tabular}{|c|c|c|c|c|c|}
\hline $\begin{array}{l}\text { PHAGES USED AND } \\
\text { INPUT RATIO }\end{array}$ & \begin{tabular}{|c} 
TOTAL \\
MULIT- \\
PUICIYY \\
OF IN- \\
PBCTION
\end{tabular} & $\begin{array}{c}\text { TOTAL } \\
\text { NOTBER } \\
\text { OF } \\
\text { PLAQRS } \\
\text { ANA- } \\
\text { LYZED }\end{array}$ & $\begin{array}{c}\text { PURE } \\
\text { WILD } \\
\text { TYPE } \\
\text { PIAQUES }\end{array}$ & \begin{tabular}{|l} 
PURE \\
MU- \\
TANT \\
PIA- \\
QUES
\end{tabular} & $\begin{array}{l}\text { MTXXD } \\
\text { PLA- } \\
\text { QUES }\end{array}$ \\
\hline $\begin{array}{l}\mathrm{P} 2 \text { and } \mathrm{P} 2 \text { vir } \\
2.5: 1\end{array}$ & 14 & 169 & 123 & 33 & 13 \\
\hline $\begin{array}{l}\mathrm{P} 2 \text { and } \mathrm{P} 2 \text { vir } \\
2.5: 1\end{array}$ & 14 & 16 & 11 & 2 & 4 \\
\hline $\begin{array}{l}\mathrm{P} 2 \text { and } \mathrm{P} 2 r d l^{*} \\
1: 1\end{array}$ & 20 & 27 & 5 & 12 & 10 \\
\hline
\end{tabular}

* $\mathrm{P} 2$ rd $l$ is a plaque type mutant of P2; the mutations involved will be described in a future publication.

mutants of $\mathrm{P} 2$ preexisting in the $\mathrm{P} 2$ clones, they ought to be distributed clonally. That possibility is thus ruled out.

Plaque formation on B by P2 may be due then either to the presence of exceptional physiological variants of $\mathrm{P} 2$ capable of growing on $\mathrm{B}$ or to the presence of exceptional B cells able to accept P2. In both cases one must assume that growth in B causes a transformation of $\mathrm{P} 2$ into P2B.

To decide the issue, experiments were tried in which $B$ cells were infected mixedly with P2 and either one of two plaque type mutants of $\mathrm{P} 2$, and then plated in the presence of more B cells. If the few plaques formed under these conditions stemmed from rare phage variants, the probability of coincidence of variant particles of both parental types in the same B cell would be quite negligible. Actually, it was found in such experiments that a high proportion of the mixedly infected B cells liberating P2B did liberate both kinds of P2B (table 9). The true proportion of B cells yielding both types is even higher than shown by the data in table 9 since in these experiments a large number of unadsorbed phage particles of both types had to be plated together with the mixedly infected $B$ cells, and these contributed to the classes of unmixed plaques. The simplest interpretation of these results is that populations of B cells contain a few exceptional cells able to accept $\mathrm{P2}$ and transform it into P2B. The causes of this heterogeneity of the B cells are unknown.

An alternative explanation would be to imagine that exceptional P2 particles able to grow on B also facilitate the growth of other P2 particles which may be present in the same cell. This interpretation is made unlikely by experiments of mixed infection of B cells with P2B vir and P2 (multiplicities of infection 0.5 and 4.4, respectively): only phage of the vir type, which is derived from the parent phage able to grow on $B$, was recovered in the progeny. Thus, the presence of P2B vir in the same B cell did not facilitate the growth of P2 particles and their transformation into $\mathrm{P} 2 \mathrm{~B}$.

\section{DISCUSSION}

There is a practically complete similarity between the P2 and the $\lambda$ systems. Both are examples of a highly efficient transformation of the infecting phage by one type of host cell (P2B by Sh and $\lambda$ by C) and of a rare, but also highly efficient, transformation in the opposite direction by another type of host cell (P2 by B and $\lambda \mathrm{C}$ by $\mathrm{S})$. The two pictures are superimposable even as to the frequency of the latter transformation (figure 1). Therefore, we can simplify the discussion by confining it to one of the cases, say, the system P2-P2B.

P2B differs from $\mathrm{P} 2$ by its ability to grow in $\mathrm{B}$. One cycle growth experiments of P2B in Sh show that the amount of transfer of this property to the phage progeny, if any, is extremely small. The efficiency of the transformation is too high to be explained in terms of mutation and selection.

On the other hand, the experiments on the dis- 
tribution of the rare P2 particles that form plaques on $B$ make it also very unlikely that the change of P2 into P2B is due to a mutation. Similar experiments showed that the same conclusion is valid for the change of $\lambda \mathrm{C}$ into $\lambda$.

The fact that no significant difference was found in the composition of the phage yielded by $C(\lambda)$ and $C(\lambda C)$, as to its ability to grow on $S$,

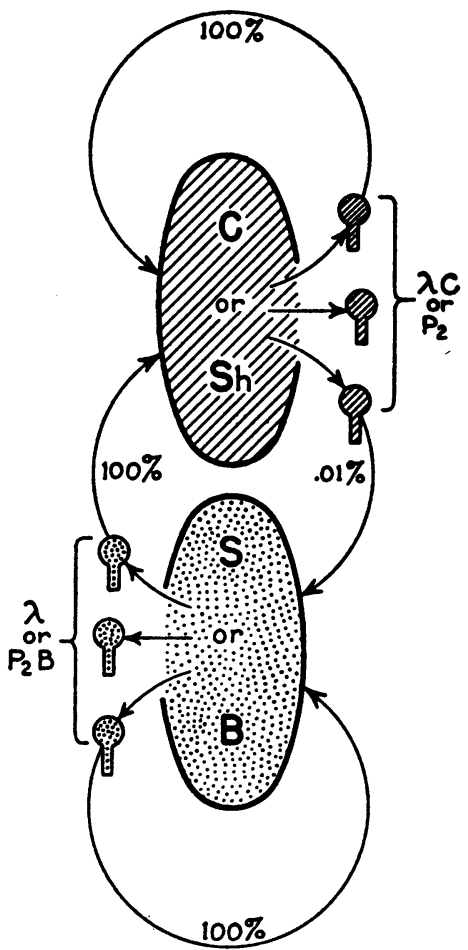

Figure 1. Homologies between the phage P2 and $\lambda$ systems of host range variation. Lines and stipples in the phages represent phage structures whose specificity is completely or almost completely determined by the host cells in which the phage was produced and which are similarly lined or stippled. The percentages indicate the efficiency of plating of a phage on the type of host indicated by the arrow.

[confirmed by parallel results on $\mathrm{Sh}(\mathrm{P} 2)$ and $\mathrm{Sh}(\mathrm{P} 2 \mathrm{~B})]$ is also evidence that these changes are not due to mutation.

We must assume then the existence of a phage structure which: (a) is required at some point in the chain of reactions leading to phage reproduction; (b) is determined completely or almost completely by the host cell (figure 1 ). The reaction for which this structure is required takes place subsequent to the adsorption of the phage onto the cell and precedes the sequence of events leading to the death of the cell. This reaction can take place and allow phage reproduction only when certain conditions of compatibility between the phage structure involved and the host cell are fulfilled (e.g., P2 or P2B on Sh; P2B on B; $\lambda$ or $\lambda C$ on $C ; \lambda$ on $S$ ). When this is not the case, the reaction has a very low probability of being successful, depending largely, if not completely, on the physiological conditions of the cells (e.g., $\mathrm{P} 2$ on $\mathrm{B} ; \lambda \mathrm{C}$ on $\mathrm{S}$ ).

Our cases resemble closely the observations described by Luria and Human (1952). Certain B/4 mutant strains of $E$. coli, strain B, upon infection with phage T2 or T6, liberate a modified phage form $\left(T^{*} 2\right.$ or $\left.T^{*} 6\right)$. This has lost almost completely the ability to grow on $\mathrm{B}$ and on its mutants (including the one in which it has originated) but can still grow on Sh. The new property is lost in one growth cycle on Sh or on the rare B cells that, under certain physiological conditions, accept the modified phage. In terms of our model, the compatibility conditions are fulfilled for T2 (or T6) with all three types of bacteria, but for the modified phage with Sh only. In contrast to both cases described in this paper, Luria and Human's mutants of strain B do not accept the phage they produce and modify although they adsorb it and are killed by it. The reaction performed by the host determined structure takes place in this case between host killing and completion of phage reproduction.

Other cases of host controlled phage variation similar to ours have been found recently in phage T1 by N. Collins Bruce (personal communication) and in another coliphage (Kopper and Long, 1952) by M. Lieb (personal communication).

Cases of phage variation which could be interpreted along the lines proposed in this discussion have been reported previously in the literature (Craigie and Yen, 1938; Burnet, Keogh, and Lush, 1937). In most of these cases it is difficult to establish from the published data how many passages through the transforming host were made before the change was studied. ${ }^{3}$ Clearly, the

${ }^{3}$ After this manuscript had been completed, Dr. E. S. Anderson of the Central Enteric Reference Laboratory, Public Health Laboratory Service (Medical Research Council), London, informed us that some unpublished experiments carried out by himself and Dr. A. Felix in 1947 show that at least some of the variations observed with Vi- 
cases for which many passages are necessary to produce the transformations are quite different from ours. Animal viruses are known which only after repeated passages through a new host lose at least part of their virulence for a former host. These transformations are probably not due to host controlled variation.

Nongenetic variations in viruses, determined by the host, can be clearly recognized only if upon passage of virus through the new host, the virus is analyzed after a single growth cycle. If the new virus is analyzed only after a series of cycles of growth on the new host, it is virtually impossible to distinguish between phenotypic variation and genetic variation coupled with selection.

In our cases the compatibility with certain hosts was the only character with respect to which variation was detected. This may be due to the methods which first brought these cases to the attention of the observers. It should be quite feasible to screen for cases of host controlled variation with respect to serological specificity, sensitivity to ultraviolet radiation, and other properties.

With respect to the compatibility with the host bacteria, the available material can be classified as follows: (1) Gain in compatibility with passage host (P2 passed on $\mathrm{B}, \lambda \mathrm{C}$ passed on S). (2) No change in compatibility with passage host (P2B passed on Sh, $\lambda$ passed on C). (3) Loss in compatibility with passage host (T2 passed on $B / 4)$.

The variation appears to be sometimes adaptive, sometimes neutral, sometimes de-adaptive with respect to the passage host. Thus, we are not dealing with an intrinsic mechanism which makes the phage structure concerned necessarily more fit for the host bacterium. However, the fact that some of these variations are adaptive may not be due to a simple coincidence. It is conceivable that a genetic basis for phenotypic adaptation to a variety of passage hosts, even of limited efficiency, could have been selected, especially in cases in which the host-environment of the viruses showed wide fluctuations in composition.

\section{SUMMARY}

Two analogous host-virus systems, each involving a bacteriophage and two bacterial strains,

phage II of Craigie and Yen follow the patterns described in this paper, and cannot be explained on the basis of a selection of host-range mutants. are described. In both cases, the phage passed through one of the host strains is able to grow on both strains, whereas the phage passed through the other host strain has an exceedingly low chance of growing on the first one. The few particles that grow on the first strain readapt to it. The changes in the infective properties of the phage occur in one growth cycle and do not involve mutation and selection. The interpretation proposed assumes the existence of a phage structure, the specificity of which is completely or almost completely under control of the host cell, and which is required for some step in the process of phage multiplication.

\section{REFERENCES}

Adams, M. H. 1950 Methods of study of bacterial viruses. In Methods in medical research. Vol. 2, 1-73. The Year Book Publishers, Chicago.

Bertani, G. 1951 Studies on lysogenesis. I. The mode of phage liberation by lysogenic Escherichia coli. J. Bact., 62, 293-300.

Burnet, F. M., Keogh, E. V., ANd Lush, D. 1937 The immunological reactions of the filterable viruses. Australian J. Exptl. Biol. Med. Sci., 15, 227-368.

Craigie, J., and Yen, C. H. 1938 The demonstration of types of $B$. typhosus by means of preparations of type II Vi phage. I. Principles and techniques. Can. J. Public Health, 29, 448-463.

Kopper, P. H., and Long, G. 1952 An uncommon type of bacteriophage. Nature, 169, 331.

Lea, D. E., and Courson, C. A. 1949 The distribution of the numbers of mutants in bacterial populations. J. Genetics, 49, 264-285.

LURIA, S. E. 1945 Mutations of bacterial viruses affecting their host range. Genetics, 30, 84-99.

LURIA, S. E. 1951 The frequency distribution of spontaneous bacteriophage mutants as evidence for the exponential rate of phage reproduction. Cold Spring Harbor Symposia Quant. Biol., 16, 463-470.

Luria, S. E., aNd Delbrưck, M. 1943 Mutations of bacteria from virus sensitivity to virus resistance. Genetics, 28, 491-511.

Luria, S. E., and Human, M. L. 1952 A nonhereditary, host-induced variation of bacterial viruses. J. Bact., 64, 557-569.

Lwoff, A., Siminovitch, L., and KJeldgard, N. 1950 Induction de la production de bactériophages chez une bactérie lysogène. Ann. inst. Pasteur, 79, 815-859.

Weigle, J. J., and Delbrück, M. 1951 Mutual exclusion between an infecting phage and a carried phage. J. Bact., 62, 301-318. 